\title{
Conservative management of CIN2 p16 positive lesions in women with multiple HPV infection
}

\author{
Maria Teresa Bruno ${ }^{1 *}$ D , Guido Scalia ${ }^{2}$, Nazario Cassaro ${ }^{3}$, Maria Costanzo $^{2}$ and Sara Boemi ${ }^{1}$
}

\begin{abstract}
Background: According to the 2006 American Society for Colposcopy and Cervical Pathology guidelines, positive CIN2 p16 in women over the age of 25 should be managed with excisional treatment. However, excisional treatment is associated with physical, psychological and obstetric morbidity and can have a negative impact on sexual function. In our study we sought to identify a clear management strategy, addressing the impact of routine use of p16 immunohistochemistry in this population and identify appropriate criteria for patient selection with the aim of reducing over-treatment.
\end{abstract}

Method: We studied the medical records of 130 patients who had undergone laser therapy for CIN2. Each patient underwent colposcopy, biopsy and HPV test and were tested for p16 protein,. Patients were divided based on HPV infection into: single infections, multiple infections. All patients underwent ZTA laser therapy with follow-up (2-year follow-up).

Statistical analysis: Contingency tables were created to evaluate the correlation between single, multiple and CIN2+ infections. Values with $p<0.05$ were considered statistically significant.

Results: Single infections had a histological regression of $61.8 \%$ (21/34) and a histological persistence rate of 35.3\% (12/34), which was greater than the multiple infection rate. The common characteristic that the women with persistence and progression had was the dimension of the lesion and the genotype 16. Ten cases of histological persistence and the only case of progression had one lesion greater than three quarters of the cervix.

Conclusions: With the progress of our understanding of the natural history of infection from human papillomavirus and the increasing use of colposcopy, thanks to the addition of HPV genotyping and the technique of immunohistochemistry, conservative management of these lesions is now possible.

Keywords: HPV infection, Multiple HPV infection, CIN2, p16 protein, Colposcopy, Laser-therapy, LEEP

\footnotetext{
* Correspondence: mt.bruno@unict.it

'Department of General Surgery and Medical Surgery Specialties, Gynecological Clinic, University of Catania, Catania, Italy

Full list of author information is available at the end of the article
}

(C) The Author(s). 2020 Open Access This article is licensed under a Creative Commons Attribution 4.0 International License, which permits use, sharing, adaptation, distribution and reproduction in any medium or format, as long as you give appropriate credit to the original author(s) and the source, provide a link to the Creative Commons licence, and indicate if changes were made. The images or other third party material in this article are included in the article's Creative Commons licence, unless indicated otherwise in a credit line to the material. If material is not included in the article's Creative Commons licence and your intended use is not permitted by statutory regulation or exceeds the permitted use, you will need to obtain permission directly from the copyright holder. To view a copy of this licence, visit http://creativecommons.org/licenses/by/4.0/ The Creative Commons Public Domain Dedication waiver (http://creativecommons.org/publicdomain/zero/1.0/) applies to the data made available in this article, unless otherwise stated in a credit line to the data. 


\section{Background}

Cervical cancer is still a major cause of cancer death in women around the world [1,2], particularly in areas with scarce resources. Human papillomavirus (HPV) infection is a sexually transmitted disease whose prevalence of various genotypes shows significant differences worldwide [3]; to date, over 100 types of HPV have been identified, 18 of which are associated with cervical carcinogenesis. Persistent infection with High-Risk Human Papilloma Virus (hr HPV) is necessary for the development, maintenance and progression of CIN (Cervical Intraepithelial Neoplasia) lesions. However, only a small percentage of infected women develop CIN2 + (CIN2, CIN3, SCC). The diagnosis of CIN is notoriously complicated due to the variability of interpretation of the clinical picture among anatomical-pathologists [4]. In particular, while CIN1 and CIN 3 are easily diagnosed and cause no doubts for pathologists, CIN2 is an equivocal diagnosis, poorly reproducible, which includes lesions that behave like CIN1 and CIN3 so much so that many experts doubt the existence of CIN2. Women under 25 years of age eliminate HPV efficiently, registering a spontaneous regression of CIN within two years; 70$94 \%$ of low-grade squamous intraepithelial lesions (LSIL); $65 \%$ of high-grade squamous intraepithelial lesions (HSIL) [5], leading to recommendations to not immediately treat CIN2 in young women [6]. The current knowledge on CIN2 regression rates in women over 25 years of age is poor [5]. Uncertainty regarding the natural history of CIN2 also casts doubt on its potential for spontaneous regression, and it is possible that the regressive nature of CIN2 depends, in some way, on the single pathologist who carried out the diagnosis.

In March 2012, the College of American Pathologists and the American Society for Colposcopy and Cervical Pathology in collaboration with 35 stakeholder organizations, held a consensus conference called the LAST Project (Lower Anogenital Squamous Terminology). The recommendations of this project include the use of a uniform two-level terminology, in parallel with the terminology of the cytological relationship of the Bethesda System, to describe the histology of the squamous disease associated with human papillomavirus in all the tissues of the anogenital tract. The two levels reflect the biology of the viral infection: one infective or productive phase, low-grade squamous intraepithelial lesion (LSIL), and a true preneoplastic lesion, high-grade squamous intraepithelial lesion (HSIL). The recommendations of the LAST Project offer a solution for the equivocal category of CIN2, which cannot be differentiated in a reliable way only from histopathological data.

The LAST Project (Darragh, 2012) [7] shows that the addition of p16 staining significantly improves the reliability of CIN2 diagnosis, [8] the use of p16 is advised to confirm the diagnosis of a high-grade lesion when there is a diagnosis of CIN2 based on hematoxylin and eosin morphology. If a sample of "CIN 2" is positive for $\mathrm{p} 16$, it should be classified as "HSIL"; if p16 is negative, it should be classified as "LSIL". Positive p16 staining of squamous cells in all the thickness of the epithelium correlates well with the diagnosis of HSIL. p16 is already widely used by pathologists in addition to cervical histopathology. From here we have the therapeutic implications that help the clinician: CIN2 p16 negative is equal to CIN1, undergoes follow-up, CIN2 p16 positive (promoted to CIN3) undergoes excisional treatment according to the guide lines of the American Society for Colposcopy and Cervical Pathology of 2006, with the aim of identifying misdiagnosed invasive or microinvasive forms on the histological sample (found in up to $8-12 \%$ of the cones carried out for CIN2-3/CIS). These treatments are destructive and can be associated with acute side effects and long-term reproductive morbidity. Are we sure that the excisional treatment of CIN2 p16 positive is not an overtreatment?

The aim of this study was to evaluate the efficacy of conservative treatment of high-grade intraepithelial cervical neoplasia (CIN2 p16 positive) by means of $\mathrm{CO}^{2}$ laser by means of the evaluation of relapse at the 2-year follow-up.

\section{Methods}

We studied the medical records of 130 patients who, from April 2015 to April 2017, had undergone laser therapy for CIN2 at the outpatients' clinic of Colposcopy of the Gynecology Unit of the University Hospital of Catania (University of Catania, Italy) and we selected the women who met the following inclusion criteria:

- Women between the ages of 25 and 45;

- Patients with histological diagnosis of CIN2;

- Protein p16 positive;

- Patients who had undergone HPV test;

- Patients with visible squamo-columnar junction;

- Women without cervical pathology previously;

- Patients without immune system pathologies;

- Patients who had completed at least two years of follow-up;

- Patients who were not pregnant.

Only 64 patients met the inclusion criteria, from whom we obtained the following clinical data: patient's age, type of pathology, HPV sample, lesion dimensions, method of treatment, data of follow-ups, pretreatment viral genotype, post-treatment HPV genotype and cases of relapse. Each patient underwent colposcopy, specific biopsy and an HPV test. Patients were divided based on HPV infection into: single infections (34 cases), multiple 
infections (30 cases). All patients were tested for histologic p16 protein, and then underwent ZTA laser therapy with follow-up. The follow-up was carried out every six months for the first year after treatment then once a year.

At each follow-up the patients were examined by Pap test and colposcopy, moreover, cytological ectoendocervical samples were taken and placed in a ThinPrep solution. The samples were then sent to the laboratory for total DNA and RNA extraction and for viral DNA genotyping by means of genetic amplification followed by hybridization with specific probes for genotypes able to identify most HPV genotypes of the genital region [28 genotypes of high-risk $\operatorname{HPV}(16,18,26,31$, $33,35,39,45,51,52,53,56,58,59,66,68,73,82)$, lowrisk genotypes $(6,11,40,43,44,54,70)$ and undefined risk $(69,71,74)]$. The commercial method used was the MAG NucliSenseasy system (bioMerieux SA, Marct l'Etoile, France).

Colposcopy was carried out using a Zeiss OPM1F colposcope (Carl Zeiss, Jena, Germany) and applying acetic acid and a solution of Lugol's iodine.

The HPV genotype was classified as follows: 1) negative; 2) HPV 16; and 3) hr. HPV (HPV18, 31, 33, 45 and other hr). The laser procedure was carried out in outpatient day-surgery by expert personnel. Vaporization was carried out using a Sharplan $\mathrm{CO}^{2}$ laser (ESC Sharplan, Yokneam, Israel) with a maximum power of $30 \mathrm{~W}$, used continuously. The diameter of the beam varied from 0.5 to $1 \mathrm{~mm}$, guided by a micromanipulator, to an average depth of vaporization of $6 \mathrm{~mm}$. Power varied from 600 to $1200 \mathrm{~W} / \mathrm{cm}^{2}$. The $\mathrm{CO}^{2}$ laser was connected to a Zeiss OPMI colposcope (Carl Zeiss. Oberkochen, Germany). The distal limits of the lesion were delineated by $3 \%$ acetic acid. The final state after two years of follow-up was classified as progression if the histologic showed a CIN3, persistence if the lesion was CIN2, regression if the histologic was negative or LSIL/CIN1, viral persistence if the HPV test was positive for the same genotype as after treatment.

\section{Statistical analysis}

The statistical analysis of the data was carried out with the software package SPSS 15.0 (SPSS Inc.; Chicago, IL, USA). The analysis of the data was made using the $x^{2}$ test and, if necessary, Fisher's exact test was used to
Table 2 Tests used during follow-up in the study group

\begin{tabular}{|c|c|c|c|c|c|}
\hline \multirow[t]{2}{*}{ Outcome } & \multirow[t]{2}{*}{ Total } & \multicolumn{2}{|c|}{ HPV Test } & \multirow[t]{2}{*}{ Histology } & \multirow[t]{2}{*}{ ColposcopyExame } \\
\hline & & pos & neg & & \\
\hline Progression & 1 & 1 & 0 & $1 \mathrm{CIN3}$ & Type1 TZ \\
\hline Persistence & 13 & 13 & 0 & 13 CIN2 & Type1 TZ \\
\hline Regression & 50 & 25 & 25 & 50 CIN1/ neg & Type1 TZ \\
\hline
\end{tabular}

calculate the statistical significance ( $p$ value) of the difference between groups. Contingency tables were created to evaluate the correlation between single, multiple and CIN2+ infections. Values with $p<0.05$ were considered statistically significant.

\section{Results}

The average age of the 64 women included in the study was 36.4 years. Progression, regression and persistence rates of CIN2 are shown in Table 1. The tests used during follow-up in the study group are shown in Table 2. At the end of the 24 months of monitoring, we found a histological regression rate of $78.1 \%(50 / 64)$, a viral persistence rate of $50 \%(25 / 50)$ and 13 cases of histological persistence $(20.3 \%)$. One case of progression to CIN3 was found at the 24-month follow-up. Among the women who had regression (50 cases), this was found at the six month follow-up in 36 cases. The prevalent genotype was HPV16 (41/64). Stratifying the women by type of HPV infection, single infections had a histological regression of $61,8 \%(21 / 34)$, the histological persistence rate, $35,3 \%(12 / 34)$, was greater than the multiple infection rate. We had 8 cases of viral persistence $(33,3 \%)$ and one case of progression (Table 3). Multiple infections had 96.7\% (29/30) histological regression, $58.6 \%$ viral persistence $(17 / 29)$ and only one case of histological persistence, $3.3 \%(1 / 30)$, there were no cases of progression (Table 4). The single infection had an OR of 17.95 (CI $95 \%=2.18-148.09$ ) compared to multiple infection.

As regards genotyping, the lesions were all caused by a high-risk genotype, even in multiple infection the most common genotype was 16 (16/30) 53.3\%.

The common characteristic that the women with persistence and progression had was the dimension of the lesion on the cervix and genotype 16. Ten cases of histological persistence and the only case of progression had one lesion greater than three quarters of the cervix.

Table 1 Prevalence of histological regression, persistence or progression after an follow-up of 24 months in the study group

\begin{tabular}{|c|c|c|c|c|c|}
\hline & \multicolumn{2}{|l|}{ Regression } & \multirow{2}{*}{$\begin{array}{l}\text { Persistence } \\
\text { histological and viral persistence }\end{array}$} & \multirow[t]{2}{*}{ Progression } & \multirow[t]{2}{*}{ Total } \\
\hline & histological regression & $\overline{\text { viral persistence }}$ & & & \\
\hline Total & $50 / 64(78.1 \%)$ & $25 / 50(25 \%)$ & 13/64 (20.3\%) & $1 / 64(1.6 \%)$ & 64 \\
\hline Single infection & $21 / 34(61.8 \%)$ & $7 / 21(33.3 \%)$ & $12 / 34(20.3 \%)$ & $1 / 34(2.9 \%)$ & 34 \\
\hline Multiple infections & $29 / 30(96.6 \%)$ & $17 / 30(58.5 \%)$ & $1 / 30(3.4 \%)$ & 0 & 30 \\
\hline
\end{tabular}


Table 3 Prevalence of histological regression, persistence and progression for HPV genotypes in the study group with a single infection

\begin{tabular}{|c|c|c|c|c|c|}
\hline Genotype & Regression & & Persistence & Progression & Tota \\
\hline & histological regression & viral persistence & histological and viral persistence & & \\
\hline & $21 / 34(61,8 \%)$ & $7 / 21(33,3 \%)$ & $12 / 34(35,3 \%)$ & $1 / 34(2,9 \%)$ & 34 \\
\hline HPV16 & 13 & 4 & 11 & 1 & 25 \\
\hline HPV31 & 3 & 1 & 0 & 0 & 3 \\
\hline HPV18 & 2 & 0 & 0 & 0 & 2 \\
\hline HPV51 & 2 & 1 & 1 & 0 & 3 \\
\hline HPV52 & 1 & 1 & 0 & 0 & 1 \\
\hline
\end{tabular}

Women with a colposcopic lesion greater than 3 quarters of the cervix had an OR of 16.67 (CI 95\% $=2.27-$ 122.22). The case of progression was treated with LEEP. All cases with viral persistence were invited to undergo HPV vaccine (data not available). There were no intraor post-operatory complications with the laser treatment to an average depth of vaporization of $6 \mathrm{~mm}$.

\section{Discussion}

Spontaneous regression rates of CIN2 of women over the age of 25 vary between 40 and $74 \%$. It is important to note that CIN2 is the least reproducible of all cervical diagnoses and it is possible that the "regression" of CIN2 is due to a subjective interpretation of the pathologist who made the diagnosis. Thus "equivocal" CIN2 lesions increase the overall regression rate and, as a consequence, the regression may have been reported in excess [9]. The diagnosis of CIN2 cannot be reliably differentiated only with histopathological data. The literature indicates a better agreement between pathologists for the diagnosis of CIN2 when the H\&E morphology is used together with p16 compared to the H\&E morphology alone. The p16 protein when positive in a CIN2 suspect gives us the confidence of having selected true CIN2 cases. These are the cases for which the spontaneous regression rate must be studied, therefore there is a need for a prospective study analysing the regression potential of true CIN2 (positive CIN2 p16) in women over the age of 25 .

Not all preneoplastic lesions will progress to cancer, therefore regardless of the positivity of p16 we cannot yet accurately predict which lesions would become malignant if left untreated. According to the 2006 American Society for Colposcopy and Cervical Pathology guidelines [6], positive CIN2 p16 in women over the age of 25 should be managed with excisional treatments. Treatment should be effective in eradicating the CIN2 lesion and have minimum adverse effects on future fertility and pregnancy outcomes, particularly in young women. However, excisional treatments are associated with physical, psychological [10] and obstetric [11] morbidity and can have a negative impact on sexual function [12-14].

In our study we sought to identify a clear management strategy, address the impact of routine use of p16 immunohistochemistry in this population and identify appropriate criteria for patient selection with the aim of reducing over-treatment.

LEEP (Loop Electrosurgical Excision Procedure), as an excisional procedure of the cervix, is the most used surgical treatment for programs of cervical screening in developed countries [15]. Some advantages of LEEP have been shown, among which is the excision of the entire transformation zone, the conservation of tissue samples for histological evaluation, low-cost equipment and the rapid rehabilitation of the cervix [11]. Thanks to these advantages, both in diagnosis and in CIN treatment, the ASCCP recommends LEEP as the excisional procedure for CIN2 +. Kyrgiou et al. [11] reported higher rates of preterm membrane rupture after LEEP compared to ablative surgery, indicating that ablative surgery such as laser vaporization should be chosen as the least invasive surgery for CIN. In a meta-analysis [16], LEEP was associated with significantly higher risks of perinatal

Table 4 Prevalence of histological regression, persistence and progression for HPV genotypes in the study

\begin{tabular}{llllll}
\hline Genotype & Regression & & $\begin{array}{l}\text { Persistence } \\
\text { histological and viral persistence }\end{array}$ & Progression \\
\cline { 2 - 3 } & histological regression & viral persistence & & $1(3.3 \%)$ & 0 \\
\hline HPV 16 & $29(96.6 \%)$ & $17(58.6 \%)$ & $1(100 \%)$ & 0 & 30 \\
Others & $15(51.8 \%)$ & $8(53.3 \%)$ & 0 & 0 & 16 \\
\hline
\end{tabular}

group with multiple HPV infections (after a 24 months of follow-up) 
mortality and preterm birth. Cochrane's revision reported three comparative studies on laser ablation with respect to LEEP [15] and did not show significative differences in the risk of residual disease in the women who had received laser ablation or LEEP. Other authors [17] reported a relapse of only $2.5 \%$ at 5 years after laser treatment of high-grade lesions, with adequate biopsies, with completely visible margins, carried out by colposcopy experts.

In the laser treated women in this study, we found only one case of progression to CIN3 and no relapse at 2 years of follow-up. Multiple infections showed a greater regression rate, unlike single infections with a greater rate of histological persistence. Undoubtedly, single infection, the presence of genotype 16 and one lesion greater than three quarters of the cervix are positively associated with persistence and progression, Castle $[5,18,19]$ reported that CIN2 caused by HPV 16 may be more likely to progress than CIN2 caused by other HR genotypes. In our study, we noticed that cases associated with multiple infection respond well to conservative therapy. Of course, the selection of cases to be treated is vital and, given that the literature [20] shows a risk of recurrence for up to 10 years for ablative treatments, strict post-treatment follow-up protocols are necessary, which advise the use of the HPV test. In recent years, several studies have shown that the HPV test performed 6-12 months after treatment is more sensitive than cytology in identifying women with recurrent disease and has a very high negative predictive value [21-23].

Therefore, in patients correctly selected such as nonimmunocompromised women and young women (younger than 25 years) with infections from HPV16 (CIN2 in the presence of HPV 16 has less probability of regression), cases in which the squamo-columnar junction is completely visible, the lesion is not very extended, and with multiple infections, a more conservative management of CIN2 p16 positive lesions is possible. Not with standing the limits of the retrospective analysis of the data, our results indicate that laser therapy is efficacious in the conservative treatment of CIN2 p16 positive lesions in carefully selected women. The persistence of the infection from high-risk HPV at follow-up is a significative predictive factor of residual or recurrent CIN after surgery $[24,25]$. Vaccination with the nonovalent HPV vaccine [26] among the patients aged between 20- and 45 -years old undergoing treatment for CIN2 is a valid addition in the prevention of recurrence.

\section{Conclusions}

With the progress in our understanding of the natural history of infection from human papillomavirus and the increasing use of colposcopy, thanks to the addition of
HPV genotyping and the technique of immunohistochemistry, conservative management of these lesions is now possible. As cervical treatment has been associated with obstetric morbidity in a successive pregnancy it is possible to stratify the risk of women with CIN2 p16 and guide the clinical management towards conservative management or cervical treatment.

Therapeutic options have evolved in the procedure of local ablation for intraepithelial lesions of the cervix.

\section{Abbreviations \\ HPV: Human Papillomavirus; CIN2: Cervical Intraepithelial Neoplasia 2; hr. HPV: high- risk HPV; LEEP: Loop Electrosurgical Excision Procedure; ATZ: Transformation Anomaly Zone; HSIL: High-grade squamous intraepithelial lesions; LSIL: Low-grade squamous intraepithelial lesions; SCJ: Squamo-columnar junction; LAST: Lower Anogenital Squamous Terminology}

\section{Acknowledgments}

We wish to thank the Scientific Bureau of the University of Catania for language support.

\section{Authors' contributions}

MTB Laser surgery and designed the study; CN and SB collected the data; MTB and SB drafted the manuscript; SG compiled the statistical data, MC performed HPV tests.

All authors read and approved the final manuscript.

\section{Funding}

No funding was involved in the preparation of this research.

\section{Availability of data and materials}

The datasets used and/or analyzed during the current study are available from the corresponding author on request.

Ethics approval and consent to participate

The study was conducted in accordance with the 1975 declaration of Helsinki. The investigations were conducted through the retrospective review of medical database. The protocol of the study was notified, according to the current legislation on observational studies provided by AIFA, to the Catania1 Ethics Committee of the Catania Polyclinic, which did not require any additions or changes to the protocol. Furthermore, the consent of the study participants was deemed unnecessary as the study only concerned the retrospective review of the medical database.

Consent for publication

Not applicable.

\section{Competing interests}

The authors declare that they have no competing interests.

\section{Author details}

'Department of General Surgery and Medical Surgery Specialties, Gynecological Clinic, University of Catania, Catania, Italy. ${ }^{2}$ Department of Biomedical and Biotechnological Sciences, Clinical Virology, University of Catania, Catania, Italy. ${ }^{3}$ Gynecological Oncology, Humanitas, Catania, Italy.

Received: 10 May 2020 Accepted: 20 October 2020

Published online: 29 October 2020

References

1. Walboomers JM, Jacobs MV, Manos MM, Bosch FX, Kummer JA, Shah KV, et al. Human papillomavirus is a necessary cause of invasive cervical cancer worldwide. J Pathol. 1999;189:12-9.

2. Jemal EP, Simard CD, et al. Annual report to the nation on the status of cancer, 1975-2009, featuring the burden and trends in human papillomavirus (HPV)-associated cancers and HPV vaccination coverage levels. J Natl Cancer Inst. 2013;105:175-201. 
3. Bruno MT, Ferrara M, Fava V, Barrasso G, Cutello S, Sapia F, Panella MM. Prevalence genotypes and distribution of human papillomavirus infection in women with abnormal cervical cytology in Catania, Italy. Giornale Ital Ostetricia Ginecol. 2016;38(5-6):376-38.

4. Castle PE, Stoler MH, Solomon D, Schiffman M. The relationship of community biopsy-diagnosed cervical intraepithelial Neoplasia grade 2 to the quality control pathology-reviewed diagnoses: an ALTS report. Am J Clin Pathol. 2007:127(5):805-15.

5. Castle PE, Schiffman M, Wheeler CM, Solomon D. Evidence for frequent regression of cervical intraepithelial neoplasia-grade 2. Obstet Gynecol. 2009:113:18-25

6. Wright TC Jr, Massad LS, Dunton CJ, Spitzer M, Wilkinson EJ, Solomon D. 2006 consensus guidelines for the management of women with cervical intraepithelial neoplasia or adenocarcinoma in situ. Am J Obstet Gynecol. 2007;197(4):340-5.

7. Darragh TM, Colgan T, Cox JT, Heller DS, Henry MR, Luff RD, et al. The lower Anogenital squamous terminology standardization project for HPVassociated lesions: background and consensus recommendations from the College of American Pathologists and the American Society for Colposcopy and Cervical Pathology. J Low Genit Tract Dis. 2012;16:205-42.

8. Bergeron C, Ordi J, Schmidt D, Trunk M, Keller T. Ridder R European CINtec histology study group. Conjunctive p1 $6^{\text {INK4a }}$ testing significantly increases accuracy in diagnosing high-grade cervical intraepithelial neoplasia. Am J ClinPathol. 2010;133:395-406.

9. Stoler MH, Schiffman $\mathrm{H}$. Interobserver reproducibility of cervical cytologic and histologic interpretations: realistic estimates from the ASCUS-LSIL triage study. JAMA. 2001;285:1500-5.

10. Palmer AG, Tucker S, Warren R, Adams M. Understanding women's responses to treatment for cervical intra-epithelial neoplasia. Br J Clin Psychol. 1993;32:101-12.

11. Kyrgiou M, Koliopoulos G, Martin-Hirsch P, Arbyn M, Prendiville W, Paraskevaidis E. Obstetric outcomes after conservative treatment for intraepithelial or early invasive cervical lesions: systematic review and metaanalysis. Lancet. 2006;367:489-98.

12. Inna N, Phianmongkhol Y, Charoenkwan K. Sexual function after loop electrosurgical excision procedure for cervical dysplasia. J Sex Med. 2010;7: 1291-7.

13. Serati M, Salvatore S, Cattoni E, Zanirato M, Mauri S, Siesto G, et al. The impact of the loop electrosurgical excisional procedure for cervical intraepithelial lesions on female sexual function. J Sex Med. 2010;7:2267-72.

14. Caruso S, Bruno MT, Cianci S, Di Pasqua S, Minona P, Cianci A. Sexual behavior of women with diagnosed HPV. J Sex Marital Ther Volume. 2019; 45(7):569-73.

15. Martin-Hirsch PL, Paraskevaidis E, Kitchener H. Surgery for cervical intraepithelial neoplasia. Cochrane Libr. 2004:1.

16. Arbyn $M$, Kyrgiou $M$, Simoens $C$, et al. Perinatal mortality and other severe adverse pregnancy outcomes associated with treatment of cervical intraepithelial neoplasia: Meta analysis. BMJ. 2008;337:a1284.

17. Fallani MG, Penna C, Fambrini M, Marchionni M. Laser $\mathrm{CO}_{2}$ vaporization for high-grade cervical intraepithelial neoplasia: a long-term follow-up series. Gynecol Oncol. 2003;91(1):130-3.

18. Wentzensen N, Walker J, Schiffman M, et al. Heterogeneity of high-grade cervical intraepithelial neoplasia related to HPV16: implication for natural history and management. Int J Cancer. 2013;132(1):148-54.

19. Bruno MT, Scalia G, Cassaro N, Boemi S. Multiple HPV 16 infection with two strains: a possible marker of neoplastic progression. BMC Cancer. 2020;20(1):444.

20. Rebolj M, Helmerhorst T, Habbema D, et al. Risk of cervical cancer after completed post-treatment follow-up of cervical intraepithelial neoplasia: population based cohort study. Br Med J. 2012;345:7882.

21. Kocken M, Uijterwaal MH, de Vries ALM, et al. High-risk human papillomavirus testing versus cytology in predicting post-treatment disease in women treated for high-grade cervical disease: a systematic review and meta-analysis. Gynecol Oncol. 2012;125(2):500-7.

22. Arbyn M, Ronco G, Anttila A, et al. Evidence regarding human papillomavirus testing in secondary prevention of cervical cancer. Vaccine. 2012:30(Supplement 5):F88-99.

23. Bruno MT, Cassaro N, Garofalo S, Boemi S. HPV16 persistent infection and recurrent disease after LEEP. Virol J. 2019;16(1):148.

24. van der Heijden E, Lopes AD, Bryant A, Bekkers R, Galaal K. Follow-up strategies after treatment (large loop excision of the transformation zone
(LLETZ)) for cervical intraepithelial neoplasia (CIN): Impact of human papillomavirus (HPV) test. Cochrane Database Syst Rev. 2015;1:CD010757.

25. Bruno MT, Ferrara M, Fava V, Rapisarda A, Coco A. HPV genotype determination and E6/E7 mRNA detection for management of HPV positive women. Virol J. 2018;15:52-6.

26. Kang WD, Choi HS, Kim SM. Is vaccination with quadrivalent HPV vaccine after loop electrosurgical excision procedure effective in preventing recurrence in patients with high-grade cervical intraepithelial neoplasia (CIN2-3)? Gynecol Oncol. 2013;130(2):264-8.

\section{Publisher's Note}

Springer Nature remains neutral with regard to jurisdictional claims in published maps and institutional affiliations.
Ready to submit your research? Choose BMC and benefit from:

- fast, convenient online submission

- thorough peer review by experienced researchers in your field

- rapid publication on acceptance

- support for research data, including large and complex data types

- gold Open Access which fosters wider collaboration and increased citations

- maximum visibility for your research: over $100 \mathrm{M}$ website views per year

At BMC, research is always in progress.

Learn more biomedcentral.com/submissions 